\title{
AC 2011-1780: FIRST GRADE STUDENTS PLANNING AND ARTIFACT CONSTRUCTION WHILE WORKING ON AN ENGINEERING DESIGN PROBLEM
}

\section{Merredith D Portsmore, Tufts University}

\begin{abstract}
Merredith Portsmore is a Research Assistant Professor in Education at Tufts University as well as the Director of Outreach Programs for Tufts Center for Engineering Education and Outreach. Merredith has the unique honor of being a "Quadruple Jumbo" having received all her four of her degrees from Tufts (B.A. English, B.S. Mechanical Engineering, M.A. Education, PhD in Engineering Education). Her research interests focus on how children engage in constructing solutions to engineering design problems. Her outreach work focuses on creating resources for K-12 educators to support engineering education in the classroom. She is also the founder of STOMP (stompnetwork.org), and LEGOengineering.com (legoengineering.com).
\end{abstract}

Brbara M. Brizuela, Tufts University Education Department 


\section{First Grade Students' Drawing and Artifact Construction for an Engineering Design Challenge}

\section{Introduction}

Design is a fundamental component of the domain of engineering. Engineering design problems are inherently "messy" - ill defined, ill structured, with incomplete information and multiple possible solutions. Models of the engineering design process serve as a framework for practicing engineers (adults) to scaffold the process. In the United States, $\mathrm{K}-12$ engineering education is a growing movement that stems from workforce needs as well as the demand for a technologically literate population. As policy makers, curriculum developers, and educators seek to include engineering in K-12, the questions of how to transpose the engineering design process for students (children) and how to structure appropriate supporting classroom activities and instruction for engaging students in engineering design problems arise.

The study described in this paper begins to tackle the question of how to include engineering design in K-12 education by exploring how first grade students engage in drawing and artifact construction when tasked with an engineering design problem. The study addresses three research questions:

1. How does a first grade student's drawing of their planned solution to an engineering design problem address the problem requirements?

2. What is the relationship between first grade students' drawing of their planned solution and their constructed artifact?

3. What is the relationship between first grade students' drawing of their planned solution and the success of their constructed artifact?

\section{Background}

Professional engineers design bridges, bubble gum, computers, cars, and more. They start by identifying a need or problem and end with carefully constructing representations of their solution through drawings, diagrams, and written descriptions. The problems engineers work on are typically ill-defined - meaning they have missing information, vague requirements, and multiple criteria for success ${ }^{1}$. Their path from problem to solution is called the engineering design process. Models of the engineering design process divide the path into multiple steps ${ }^{2,3}$. The models typically include a number of steps prior to the construction of a prototype of their solution that require the engineers to determine the requirements and constraints of the problem, research and brainstorm possible solutions, select and evaluate materials, and create drawings of their proposed solution. These preliminary actions, grouped together as planning actions for the purposes of this study, are a critical component of the engineering design process as the real world of engineering design has a number of limitations (time, resources, funding) that make hands-on trial and error difficult or impossible.

Understanding of the engineering design process steps is often a learning goal in much of the engineering education curricula and activities that are created for K-12 students. Specific 
branches of engineering (i.e., mechanical, civil, electrical, chemical) have different content knowledge but all employ the engineering design process, to different degrees, in their approach to designing solutions to problems. The prevalence of the engineering design process in K-12 is likely due to the fact that it is the universal component of all the branches of engineering. National and state standards that include engineering ${ }^{4,5}$ all include engineering design in their requirements (although they vary in their recommendations about what steps of the engineering design process young children should be learning). While design activities have been part of K12 education through other efforts such as teaching science through the design of artifacts e.g. ${ }^{6}$, 7,8 and technology education e.g. ${ }^{9,10-12}$, we know very little about how the structure of design activities, specifically which parts of the engineering design process students are exposed to and their impacts on students' abilities to plan and design solutions to engineering design problems.

This study's focus on planning addresses the lack of a consensus in existing research in the areas of general problem solving and technology education about young children's ability to plan via drawing and the role of planning in design. Research in problem solving ${ }^{13,14}$ using general, well-defined problems demonstrates that six and seven year old students (first grade age) are able to plan solutions when planning adds value to the outcome of a task -- for example planning was useful to students when it was important to make no wrong turns when solving a maze. Within the area of technology education ${ }^{9,15,16}$, researchers are divided about students' ability to engage in planning while they are designing. A number of studies ${ }^{9,11,17}$ show that students do not spontaneously engage in planning when designing and that their plans do not have a strong resemblance to their final construction. Alternatively, there have been findings that young students can make drawings that resemble their final creation ${ }^{18}$ and that planning via drawing emerges as students progress through primary/elementary schooling ${ }^{10,16}$. Within technology education, the research projects were all conducted within classroom settings; therefore, they include a number of confounding variables (peers, classroom atmosphere, teacher's understanding of design, curricula, access to materials) that make it difficult to fully interpret the results.

Understanding if young children can identify problem requirements, draw a potential solution, and construct a related solution is crucial for thinking about the role planning via drawing can have for young children in engineering design activities and the form it can take. For example, if young children are unable to understand implicit problem requirements on their own then these elements will need to be made explicit by the activity and the teacher. If children do not see the value in planning via drawing or if they are unable to use drawing as a planning tool they will need additional scaffolding and support.

\section{Methodology}

The study was conducted as one on one clinical-style interviews with first grade students. Student participants were solicited from four first grade classrooms in an upper middle class suburban Boston-area elementary school. Seventy-six first grade students were invited to participate and 31 (16 females and 15 males) students consented to fully participate in the research study.

Task Design 
The Trapped Key task served as the single engineering design task presented to students in a clinical interview setting. The task required students to design a tool to retrieve a set of two keys attached to a key ring from the bottom of a clear Plexiglas box (23" 4.5 "x4.5"; see Figure 1). The box was not fixed to the floor and the top was fully open. Students were provided with eight materials (12" pipe cleaners, 12 " wooden dowel rods [sticks], plastic spoons, unsharpened pencils, string, paperclips, round and bar magnets, and tape) as well as scissors to use to design and construct a tool to retrieve the keys.

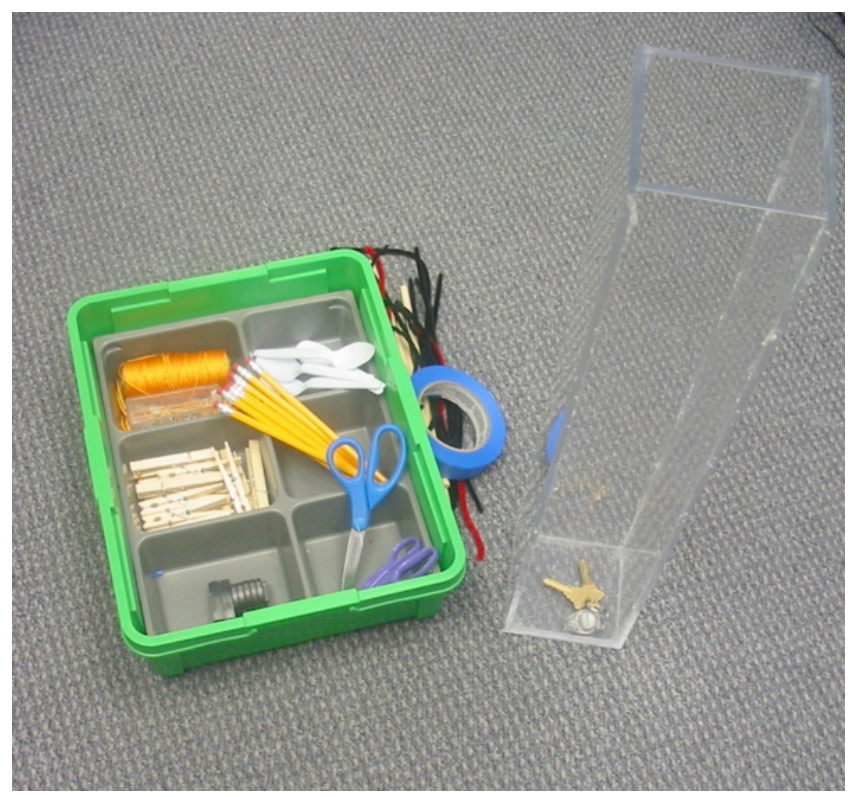

Figure 1. Trapped Key Task and Materials

The Trapped Key task, which requires students to design and construct a tool to retrieve a 2 keys on a key ring from a tall box, was created as a modified engineering design problem to work within the context of the 20 minutes limited time available in the interview. The task was also designed to focus on preliminary drawing and the relationship between drawing and success. Therefore, students were given the problem and not required to engage in formal research, brainstorming, the creation of multiple solution ideas, or the selection of a single best idea, in order to ensure that all students were able to draw and construct a solution in the designated time. However, the task was designed for students to deal with both stated and unstated (implicit) requirements and constraints. Table 1 illustrates the structure of the Trapped Key Task as an engineering design problem

Table 1. Structure of Trapped Key Task as an engineering design problem.

\begin{tabular}{|l|l|}
\hline Goal (Problem): & $\begin{array}{l}\text { Stated/Explicit- Retrieve a set of keys from the Plexiglas box (the box may not be } \\
\text { moved, nor may your hand go inside the box) }\end{array}$ \\
\hline Requirements: & $\begin{array}{r}\text { Unstated/Implicit - } \\
\text { Conceptual - The tool must address: (a) length and (b) key acquisition } \\
\text { Construction - } \\
-\quad \text { The tool must reach a minimum length of 23" } \\
-\quad \text { The tool must fit into the opening of the box 4.5" x 4.5" } \\
-\quad \text { The tool must be sturdy }\end{array}$ \\
\hline
\end{tabular}




\begin{tabular}{|l|l|}
\hline Constraints: & $\begin{array}{l}\text { Stated/Explicit - Use the materials presented } \\
\text { Unstated/Implicit -Limitations of the materials } \\
\text {-Limitations of the box dimensions }\end{array}$ \\
\hline Solution Paths: & $\begin{array}{l}\text { The materials presented for the task allowed for multiple ways of acquiring the } \\
\text { keys as well as multiple ways of combining materials to create a tool long enough } \\
\text { to reach the bottom of the box }\end{array}$ \\
\hline
\end{tabular}

The materials presented to students were selected to give students a combination of ideal and non-ideal materials (see Tables 2 and 3) for the task to allow for multiple solutions paths as well as to explore how well students understood the problem requirements. For example, students were presented with 12 " dowel rods and $73 / 8$ " pencils. Understanding the requirement of length would make the selection of the longer dowel rods more useful. Similarly, magnets and spoons could both be used to pick up keys off the floor, but the narrow box makes it difficult to get the spoons under the keys whereas magnets can pick up the keys from multiple angles or positions.

Table 2. Ideal and Non-Ideal Materials for Length.

\begin{tabular}{ll}
\hline Ideal Materials for Length & Non-Ideal Materials for Length \\
\hline Sticks - 12" long & Pencils - usable but shorter than sticks \\
\hline Pipe Cleaner - 12" long & Spoons - difficult to attach together \\
\hline String - As long as needed & \\
\hline
\end{tabular}

Table 3. Ideal \& Non-Ideal Materials for Key Acquisition.

\begin{tabular}{ll}
\hline Ideal Materials for Key Acquisition & Non-Ideal Materials for Key Acquisition \\
\hline Magnets - Attracted to keys & Clothespin - Difficult to articulate in box \\
\hline Paper Clip - Can be bent to hook of small diameter & $\begin{array}{l}\text { Tape - Difficult to stick to keys (rough surface) } \\
\text { Attracted to side of box (static) }\end{array}$ \\
\hline Pipe Cleaner - Can be bent to hook of small diameter & $\begin{array}{l}\text { Spoon - Difficult to impossible to get under keys in } \\
\text { narrow box }\end{array}$ \\
\hline
\end{tabular}

\section{Data Collection}

Each consenting student was solicited for a one-on-one interview with the researcher, first author of this study. Each individual interview was videotaped. Interviews took place in a conference room off the main school office. Participants were asked a few warm up questions about their favorite toys and out of school activities to help them become comfortable with the interviewer. Following the questions, participants were presented with the Trapped Key task and materials and given the following instructions: 
Let me tell you what we are going to do with all this stuff. It's got two parts to it. It's got a drawing part and a making part. So, you can see I've got some keys trapped in the bottom of this box. Kind of a little dangerous box. It's got some sharp edges and stuff. So, I want you to see if you can build me something that will get the keys out of the box without putting your hand in the box or moving the box. And before you build it I'm going to ask you to draw a picture of what you think you are going to make. Let's look at all the stuff you've got here so you know what you have to work with. You have pipe cleaners, super long sticks, string, obviously scissors so you can cut stuff or do whatever you want with them, all kinds of magnets, tape... And you can use any of these materials any way you want. And if you need help cutting or tying or taping you can ask me for help.

The students were not informed about the properties of the any of the materials and were not permitted to experiment with the materials prior to drawing.

Following this introduction, the task involved the following steps:

a. Drawing/Planning: participants were presented with a clipboard and paper to draw the original idea that they were going to try to build.

b. Clarification: once they had completed drawing the idea the interviewer asked them to clarify what materials they were using and labeled them on their drawing (i.e., "So this is string here? This is a magnet?").

c. Construction of artifact: participants were given 10 minutes to solve the challenge on their own following the drawing of their idea. Students who were able to construct a solution that retrieved the keys from the box in less than 10 minutes were categorized as having completed the challenge successfully. Students who were unable to create a successful solution in 10 minutes were categorized as incomplete. After 10 minutes had passed, the interviewer intervened with suggestions and helped with constructions so that all children would feel they had been able to retrieve the keys from the box. Keys were place in a corner of the box by the interviewer in the same manner for each student.

\section{Data Analysis}

The sources for the data analysis were the drawings the students made before constructing their solutions, their final constructed artifacts, and the video of the interview session. The data analysis looked to quantify and describe the drawing of the planned solution, the final constructed artifact, and the relationship between the two.

\section{Drawing of planned solution and the problem requirements and constraints}

The students' drawings were analyzed to see how they were able to plan a solution that 
addressed the engineering design problem requirements and to specifically address the first research question -- How does a first grade student's drawing of their planned solution to an engineering design problem address the problem requirements? To do this each drawing was evaluated for whether it addressed conceptual and construction requirements of tool length and key acquisition as well as the constraints related to materials and the box. Length was assessed based on three factors: (1) whether they included a material for length; (2) whether they included sufficient materials to reach the bottom of the box (a single material or combination of materials that would achieve approximately 23 inches - the distance to the bottom of the box); (3) whether the students selected ideal materials for their construction, and specifically which materials they selected (see Appendix A). Similar codes were used for analyzing the key acquisition strategy in the drawing. It was difficult to determine from the drawing whether the quantity of a particular material was sufficient for key retrieval so this category was eliminated from the key acquisition component (see Appendix B).

Students were given a Total Drawing Score (TDS) where the results of the numeric codes achieved for length in drawing (see Appendix A) and for key acquisition (see Appendix B) were added to form a cumulative score rate for how children's drawing of their planned solution addressed the problem requirements and the constraints. A maximum score of 8 would represent a drawing where length and key acquisition were addressed with sufficient ideal materials. Figures 2 and 3 shows drawings with high Total Drawing Scores (TDS=8, TDS=6) and those in Figures 4 show productions with a low Total Drawing Scores (TDS $=1$ ).

The drawing with Total Drawing Score of 8 in Figure 2 addresses length and key acquisition using ideal materials. A stick, pipe cleaner, and string are show for length, which are all ideal materials and easily measure greater than 23 " to reach the bottom of the box. The drawing includes a magnet for key acquisition, which is an ideal material.

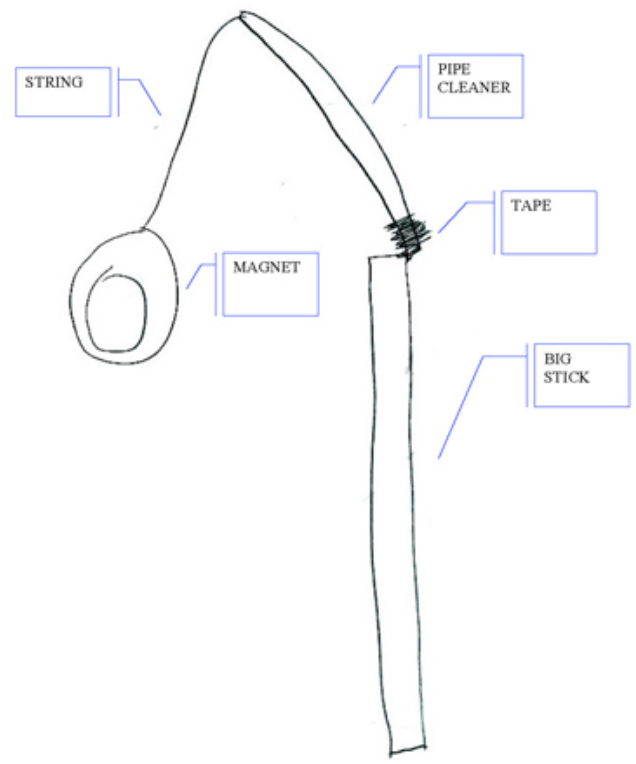

\begin{tabular}{|c|c|}
\hline Category & Score \\
\hline Addresses LENGTH & 1 (Addressed) \\
\hline $\begin{array}{r}\text { Enough material(s) for } \\
\text { LENGTH }\end{array}$ & $\begin{array}{l}2 \text { (Materials able to reach } 23 " \\
\text { or greater) }\end{array}$ \\
\hline $\begin{array}{r}\text { Ideal Materials for } \\
\text { LENGTH }\end{array}$ & 2 (All Ideal Materials) \\
\hline $\begin{array}{r}\text { Addresses Key } \\
\text { Acquisition }\end{array}$ & 1 (Addressed) \\
\hline $\begin{array}{r}\text { Ideal Materials for Key } \\
\text { Acquisition }\end{array}$ & 2 (All Ideal Materials) \\
\hline $\begin{array}{r}\text { TOTAL DRAWING } \\
\text { SCORE (TDS) }\end{array}$ & 8 \\
\hline
\end{tabular}

Figure 2. A student's drawing of their planned solution (TDS=8).

Figure 3 shows a drawing with a Total Drawing Score of 6. This drawing addressed both length and key acquisition. A stick and two pipe cleaners were shown for length (and measure greater 
than 23"). However, although it included enough materials for length the selected material of tape for key acquisition (tape) was not ideal.

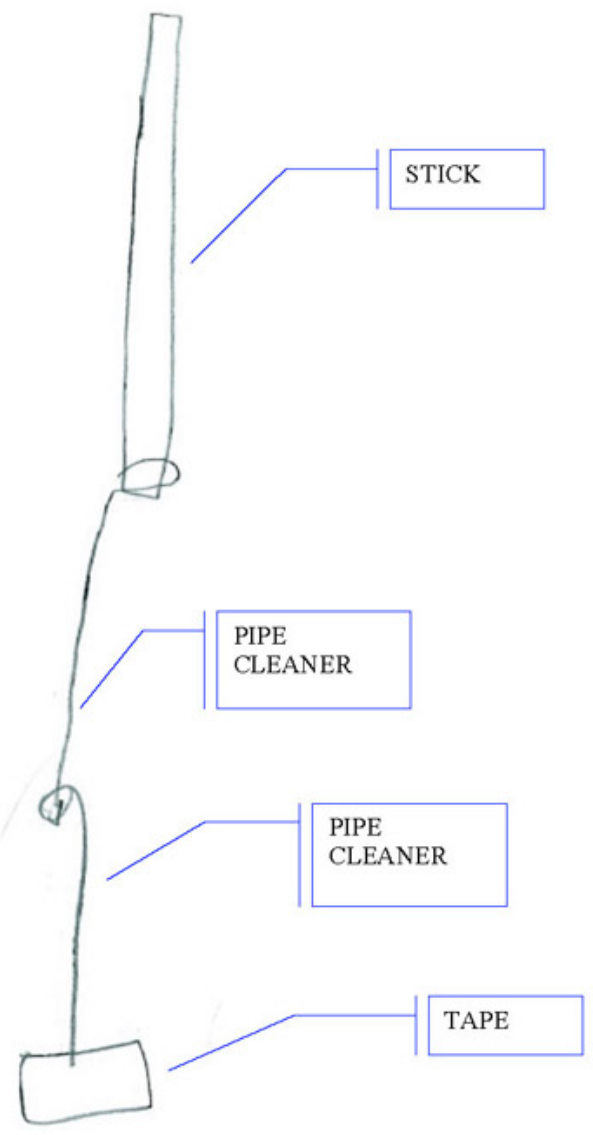

\begin{tabular}{|r|l|}
\hline \multicolumn{1}{|c|}{ Category } & \multicolumn{1}{c|}{ Score } \\
\hline Addresses LENGTH & $\mathbf{1}$ (Addressed) \\
\hline Enough material(s) for & $\mathbf{2}$ (Materials able to reach \\
LENGTH & 23” or greater) \\
\hline Ideal Materials for & $\mathbf{2}$ (All Ideal Materials) \\
LENGTH & \\
\hline Addresses Key & $\mathbf{1}$ (Addressed) \\
Acquisition & \\
\hline Ideal Materials for & $\mathbf{0}$ (No Ideal \\
Key Acquisition & Materials/Unclear) \\
\hline $\begin{array}{r}\text { TOTAL DRAWING } \\
\text { SCORE (TDS) }\end{array}$ & $\mathbf{6}$ \\
\hline
\end{tabular}

Figure 3. A student's drawing of their planned solution (TDS=6).

Figure 4 shows a drawing that did not seem to clearly address the problem. It was inferred that the selection of a material (pipe cleaner or stick) was meant to reach into the box. However, key acquisition was not addressed and the configuration of the materials would not allow the tool to reach the bottom of the box.

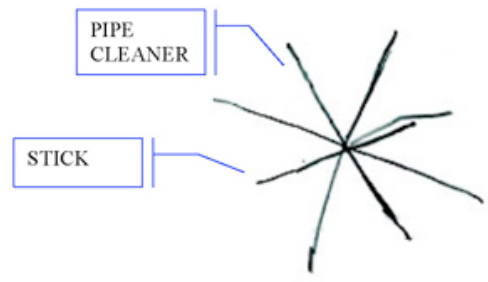

\begin{tabular}{|c|c|}
\hline Category & Score \\
\hline Addresses LENGTH & 1 (Addressed) \\
\hline $\begin{array}{r}\text { Enough material(s) for } \\
\text { LENGTH } \\
\end{array}$ & $\begin{array}{l}\mathbf{0} \text { (Materials able to reach } 23 " \\
\text { or greater) }\end{array}$ \\
\hline $\begin{array}{r}\text { Ideal Materials for } \\
\text { LENGTH } \\
\end{array}$ & $\begin{array}{l}\mathbf{0} \text { (No Ideal } \\
\text { Materials/Unclear) }\end{array}$ \\
\hline $\begin{array}{r}\text { Addresses Key } \\
\text { Acquisition } \\
\end{array}$ & $\mathbf{0}$ (Addressed) \\
\hline $\begin{array}{r}\text { Ideal Materials for Key } \\
\text { Acquisition }\end{array}$ & $\begin{array}{l}\mathbf{0} \text { (No Ideal } \\
\text { Materials/Unclear) }\end{array}$ \\
\hline $\begin{array}{r}\text { TOTAL DRAWING } \\
\text { SCORE }\end{array}$ & 1 \\
\hline
\end{tabular}

Figure 4. A student's drawing of their planned solution (TDS=1). 


\section{Relationship between drawing of planned solutions and constructed artifact}

To establish the relationship between students' drawings and their constructed artifact a relationship score was calculated by comparing the students' drawing and their constructed artifact. This relationship directly addressed the second research question - What is the relationship between first grade students' drawing of their planned solution and their constructed artifact? The relationship was separated into the two conceptual requirements for the task - length and key acquisition. The analysis focused on comparing the materials, their arrangement, and quantity used for both length and key acquisition in the drawing and artifact. A score of 3 meant that students drew all the same materials in the same configuration and quantity that they used in their final artifact (i.e., perfect match between drawing/plan and construction). A score of 2 meant that there were minor differences. This score indicated that the students retained their core idea but needed to change the position of the attachment, the material used for the attachment, or realized that they needed an additional quantity of a material they had already selected. A score of 1 indicated significant differences between the drawing/plan and the construction. This score would indicate that students may have realized the presence of a significant issue with their plan and needed to change the material arrangement or substitute for a new material. A score of 0 was selected when there were no discernable elements of the plan used in the final artifact. The scores (Length Relationship Score [LRS] and Key Acquisition Relationship Score [KARS]) were totaled for each student to generate a total score (see

Table 4).

Table 4. Total Relationship Score - Relationship Between Drawing and Artifact Scores.

\begin{tabular}{|c|c|c|c|c|}
\hline $\begin{array}{l}\text { Length Relationship Score in } \\
\text { Drawing and Artifact (LRS) }\end{array}$ & 3 - Identical & $\begin{array}{c}2-\text { Differ in } \\
\text { attachment } \\
\text { material or } \\
\text { different } \\
\text { attachment } \\
\text { position or } \\
\text { increase/decrease } \\
\text { of material } \\
\text { quantity shown in } \\
\text { drawing }\end{array}$ & $\begin{array}{l}\text { 1-Differ in } \\
\text { material } \\
\text { arrangement or } \\
\text { additional } \\
\text { materials types } \\
\text { used }\end{array}$ & $\begin{array}{c}0- \\
\text { Completely } \\
\text { Different }\end{array}$ \\
\hline $\begin{array}{l}\text { Key Acquisition Relationship } \\
\text { Score in Drawing and Artifact } \\
\text { (KARS) }\end{array}$ & 3 - Identical & $\begin{array}{c}2 \text { - Differ in } \\
\text { attachment } \\
\text { material or } \\
\text { different } \\
\text { attachment } \\
\text { position or } \\
\text { increase/decrease } \\
\text { of material } \\
\text { quantity y shown } \\
\text { in drawing }\end{array}$ & $\begin{array}{l}\text { 1-Differ in } \\
\text { material } \\
\text { arrangement or } \\
\text { additional } \\
\text { materials types } \\
\text { used }\end{array}$ & $\begin{array}{c}0- \\
\text { Completely } \\
\text { Different }\end{array}$ \\
\hline $\begin{array}{l}\text { Total Relationship Score } \\
\text { (TRS) }\end{array}$ & LRC + KARS & & & \\
\hline
\end{tabular}


A score of 6 would represent a drawing/artifact pair where the artifact was identical to the drawing. A score of 0 would represent a drawing/artifact pair where the final artifact looked nothing like the original drawing. Figures 11 through 15 show examples of Total Relationship Scores of 2 through 6 (Pictures were unavailable for TRS scores of 0 and 1).

In Figure 5, which has a Total Relationship Score of 6, the artifact perfectly matches the original drawing in the materials and attachment for length and key acquisition.
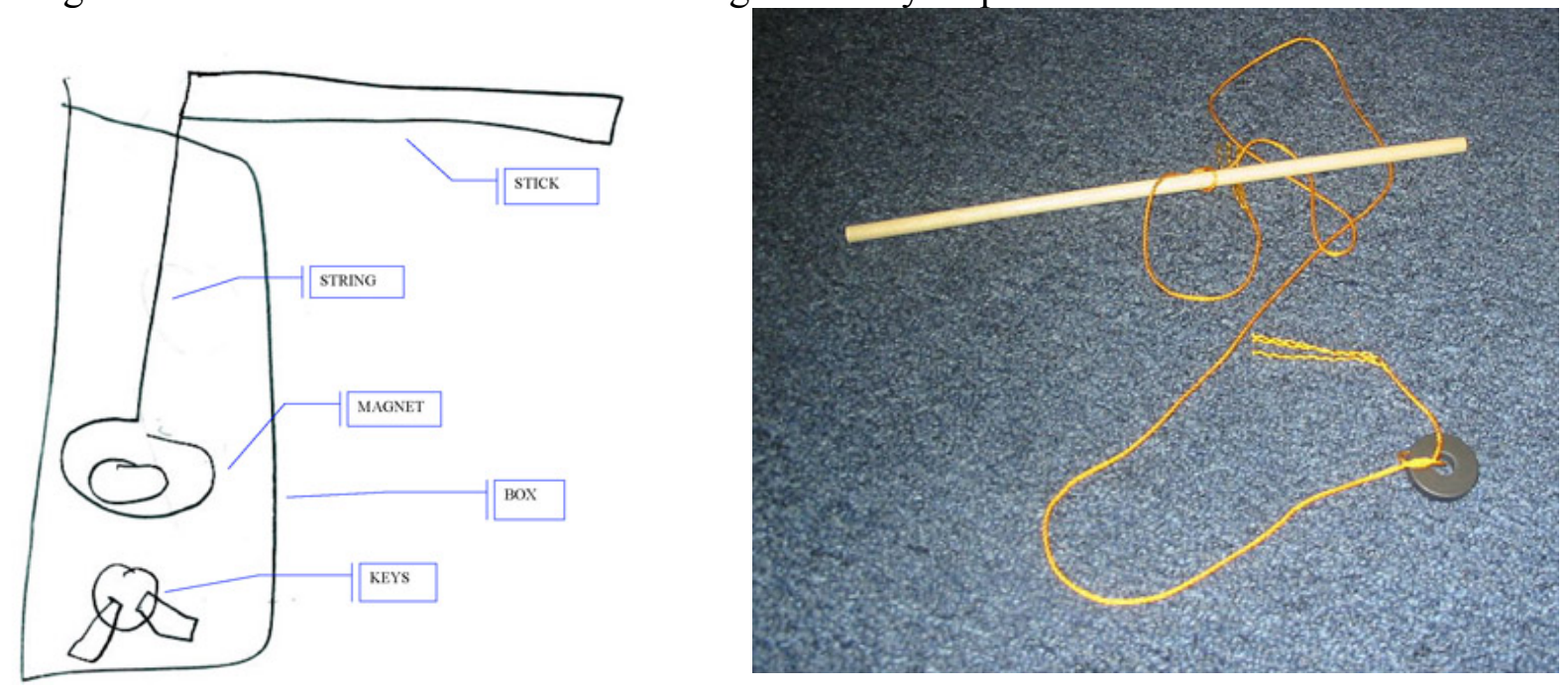

Figure 5. A drawing and artifact pair where Total Relationship Score $=6 .(\mathrm{LRS}=3 \mathrm{KARS}=3)$.

Figure 6 has a Total Relationship Score of 4. This pair shows that between the drawing and the artifact the material quantity for length changed (a stick was eliminated) and a material (pipe cleaner) was eliminated. The significant changes to the materials for length yielded a Length Relationship Score of 1. However, the material intended for Key Acquisition (the stick) remained the same, which is why the Key Acquisition Relationship Score remained a "perfect" 3. It should be emphasized that the Total Relationship Score was designed to reflect the relationship between the ideas in the drawing and the artifact. It does not reflect the quality of those ideas. 

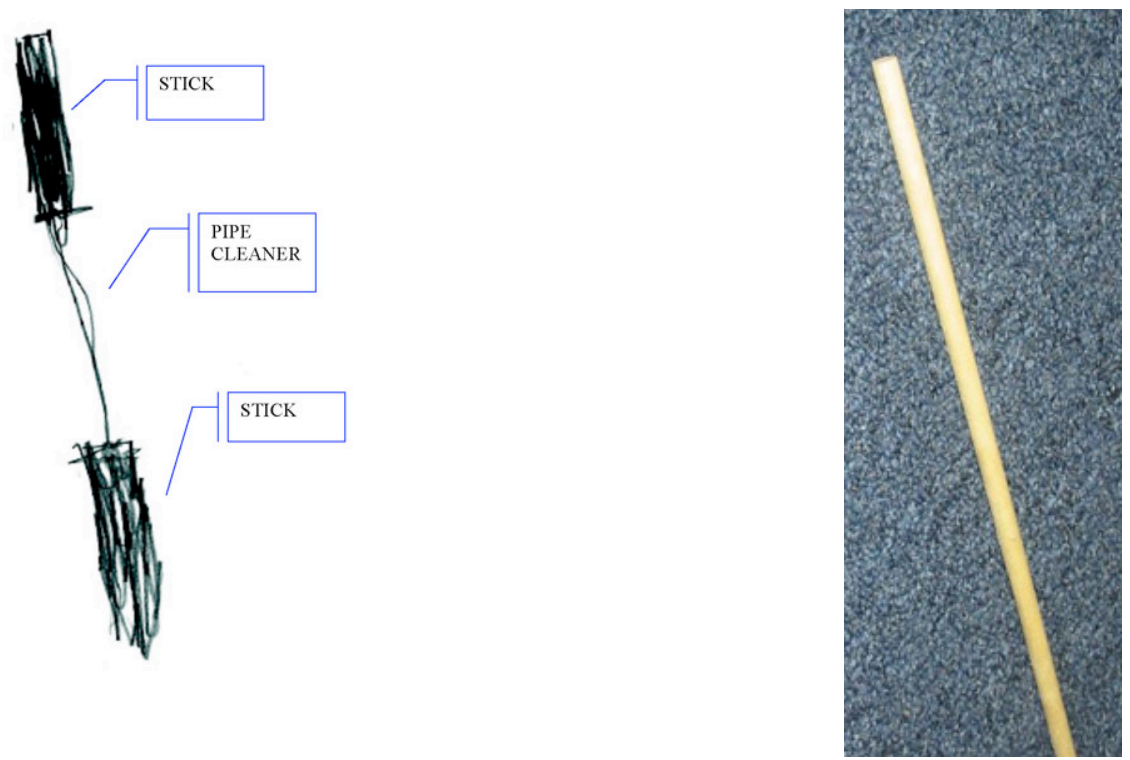

Figure 6. A drawing and artifact pair where Total Relationship Score $=4$. $(\mathrm{LRS}=1 \mathrm{KARS}=3)$.

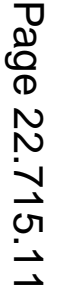


Figure 7 has a Total Relationship Score of 2. Tape, not shown in the drawing, was added to the artifact to attach the stick and pipe cleaner, which yielded a Length Relationship Score of 2 for the pair. The material for key acquisition was completely changed from tape to a magnet (attached with paper clips). This total change yielded Key Acquisition Relationship Score of 0.
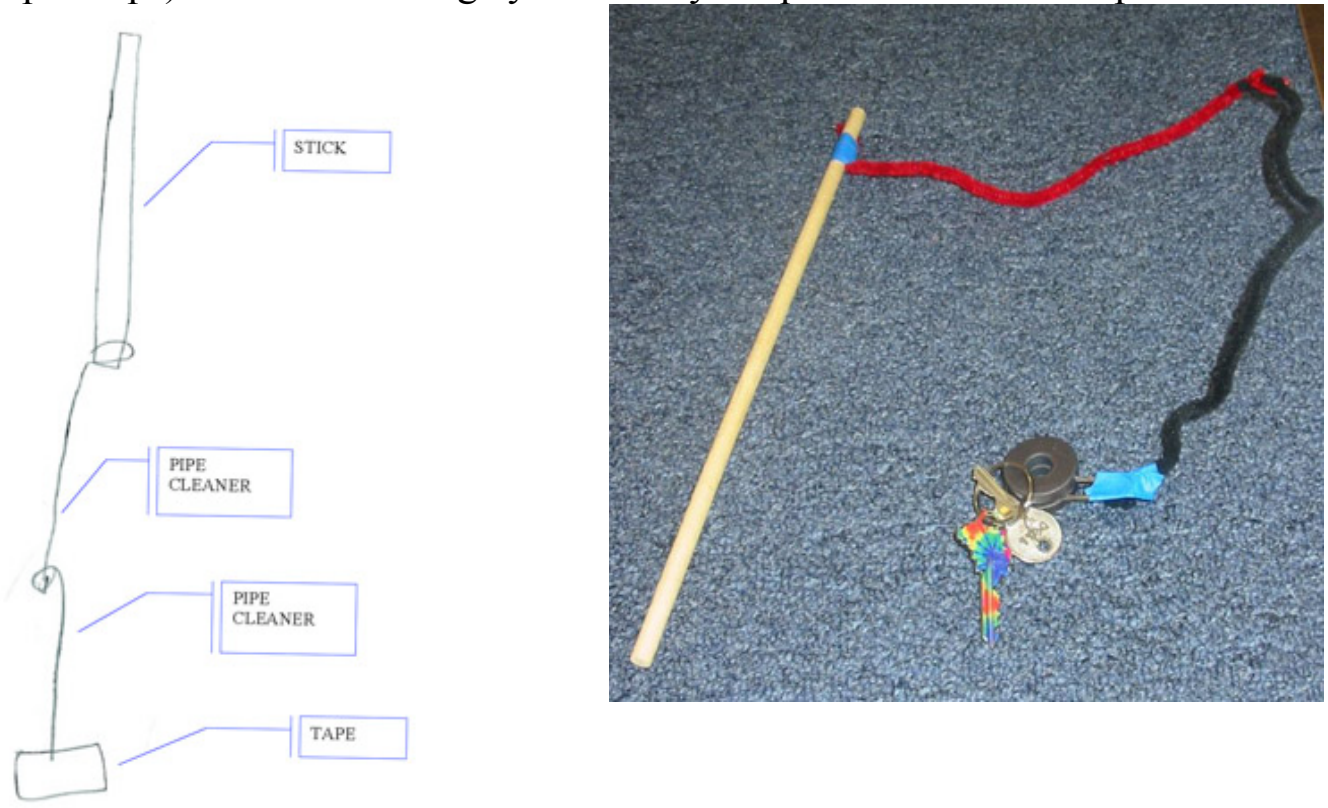

Figure 7. A drawing and artifact pair where Total Relationship Score $=2$. $(\mathrm{LRS}=2 \mathrm{KARS}=0)$.

The total relationship score was only calculated for successful solutions (solutions that retrieved the keys in under 10 minutes) based on the final artifact that was used to retrieve the keys from the box. It was impossible for the incomplete solutions to identify an equivalent artifact that could be used for the comparison as students in this group often had no artifact or a partial artifact at the 10-minute mark.

\section{Relationship between drawing of planned solution and the success of constructed artifact}

The videos of the interviews were used to collect information about the students' process of constructing the artifact. This information combined with the drawing scores was used to address the third research question - What is the relationship between first grade students' drawing of their planned solution and the success of their constructed artifact? Information collected included:

- Task Completion - Students who constructed a solution to retrieve the keys in 10 minutes or less were categorized as successful. Students who were unable to construct a solution to retrieve the keys were categorized as incomplete.

- Time to Complete Task -For students who created a successful solution, the time was marked from the start of their construction of their artifact (after they had completed their drawing and labeled it with the interviewer) until they extracted the keys from the box with their artifact to generate a "Time to Complete Task."

\section{Results}


A majority of students (77.4\%) were able to successfully construct an artifact in less than 10 minutes (Successful) while $22.6 \%$ of the students were not able to create an artifact in the designated time (Incomplete). Table 5 shows that the breakdown between genders. Even though boys performed slightly better than girls, Fisher's exact probability test shows that the difference was not significant $(\mathrm{p}=.23)$. Therefore, in the analysis that follows, data for the two genders are jointly considered.

Table 5. Students' performance on the Trapped Key Task by gender.

\begin{tabular}{cclc}
\hline & $\begin{array}{c}\text { Successful } \\
\text { Solution }\end{array}$ & $\begin{array}{c}\text { Incomplete } \\
\text { Solution }\end{array}$ & Total \\
\hline Females & $11(35.5 \%)$ & $5(16.1 \%)$ & 16 \\
\hline Males & $13(41.9 \%)$ & $2(6.5 \%)$ & 15 \\
\hline & $24(77.4 \%)$ & $7(22.6 \%)$ & 31 \\
\hline
\end{tabular}

Students' drawing of planned solution \& the problem requirements

The first research question asked how students' plans addressed the requirements of an engineering design problem. Analysis of the drawings of the students' planned solution showed that a majority of the students in both groups included in their drawing some materials for each of the two conceptual requirements (length and key acquisition) of the problem (see Table 6). This indicates that most students understood the conceptual problem requirements and could, in some manner, draw the materials they intended to use to address the requirements.

Table 6. Students' drawing of materials for addressing length and key acquisition.

\begin{tabular}{cccc}
\hline & Successful Solution & Incomplete Solution & Whole Group \\
\hline Addressed length & $23(95.8 \%)$ & $5(71.4 \%)$ & $28(90.3 \%)$ \\
\hline $\begin{array}{c}\text { Addressed key } \\
\text { acquisition }\end{array}$ & $20(83.3 \%)$ & $5(71.4 \%)$ & $25(80.6 \%)$ \\
\hline
\end{tabular}

A majority of students in both groups selected all ideal materials for length in their drawings or a majority of ideal and non-ideal materials for length (see Table 7). However, Fisher's exact probability test shows the difference was not significant $(p=.31)$ between the successful and incomplete groups.

Table 7. Students' drawing of Ideal Materials for Length.

\begin{tabular}{cccc}
\hline & Successful Solution & Incomplete Solution & Whole Group \\
\hline $\begin{array}{c}\text { All Ideal Materials for } \\
\text { Length }\end{array}$ & $18(75.8 \%)$ & $3(42.9 \%)$ & $21(67.7 \%)$ \\
\hline $\begin{array}{c}\text { Both Ideal and Non } \\
\text { Ideal Materials for } \\
\text { Length }\end{array}$ & $3(12.5 \%)$ & $2(28.6 \%)$ & $5(16.1 \%)$ \\
$\begin{array}{c}\text { Non-Ideal Materials or } \\
\text { No Materials for } \\
\text { Length }\end{array}$ & $3(12.5 \%)$ & $2(28.6 \%)$ & $5(16.1 \%)$ \\
\hline
\end{tabular}


The selection of ideal materials indicates that students understood the constraints of the materials and could choose ideal materials to accomplish length. However, the percentages for both the successful and incomplete groups were lower when their drawings were analyzed for whether the materials they chose were sufficient for length (able to reach the bottom of the 23 inch tall box; see Table 8). Fisher's exact probability test shows the difference between the successful and incomplete solution groups was not significant $(\mathrm{p}=.12)$

Table 8. Students' drawing of sufficient materials for length.

\begin{tabular}{cccc}
\hline & Successful Solution & Incomplete Solution & Whole Group \\
\hline $\begin{array}{c}\text { Sufficient Materials } \\
\text { for Length }\end{array}$ & $14(58.3 \%)$ & $4(57.1 \%)$ & $16(58.1 \%)$ \\
\hline Partial Materials & $9(37.5 \%)$ & $1(13.3 \%)$ & $10(32.3) \%$ \\
\hline $\begin{array}{c}\text { No Materials for } \\
\text { Length }\end{array}$ & $1(4.2 \%)$ & $2(28.6 \%)$ & $3(9.7 \%)$ \\
\hline
\end{tabular}

A majority of students in both groups (58.3\% Successful and 57.1\% Incomplete) were able to account for the length of the box in their plan by including multiple materials. Figure 8 shows an example of a drawing that included sufficient materials for length (stick, pipe cleaner, string). Conversely, Figure 9 is an example of a student thinking about the conceptual requirement for length (shown by the inclusion of a pipe cleaner) but not the actual dimensions of box (the 12" pipe cleaner would not reach the bottom of the 23 " box).

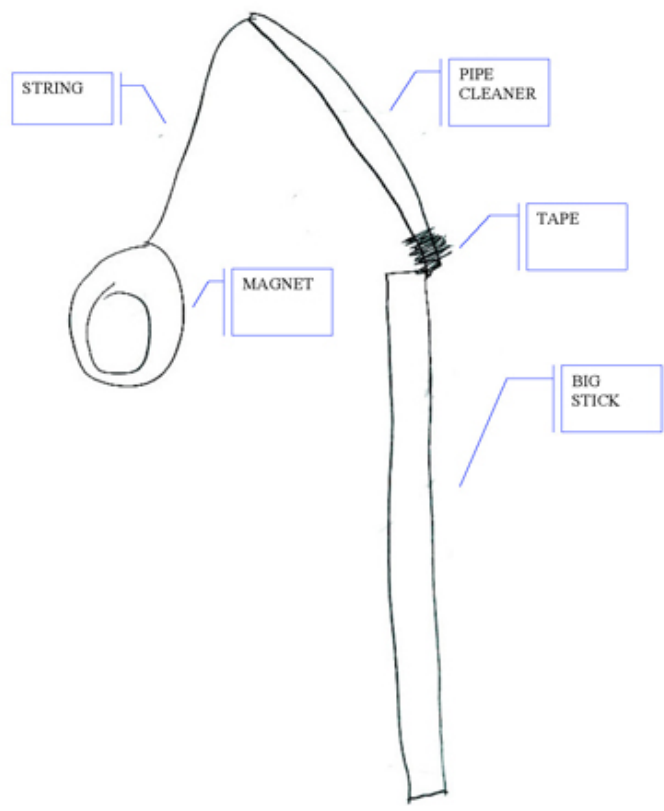

Figure 8. A drawing that included sufficient materials for length. 


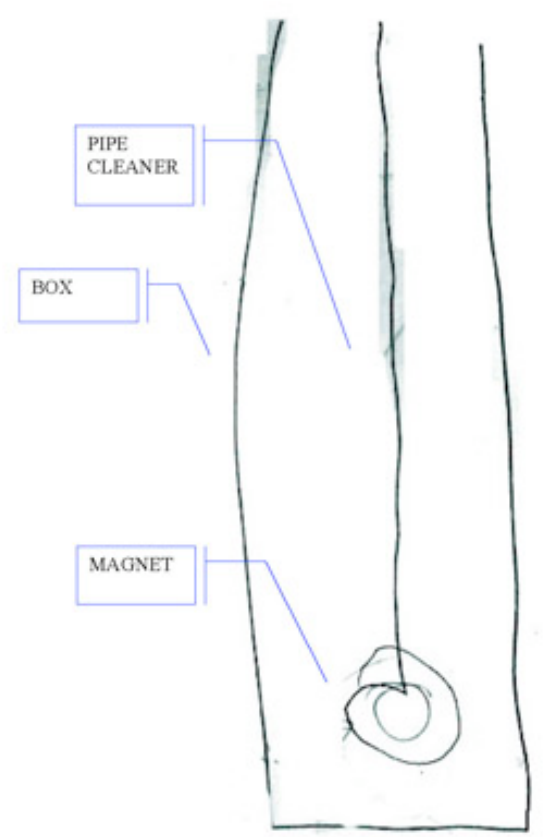

Figure 9. A drawing that included partial materials for length.

Students' drawing of ideal materials for key acquisition (see Table 9) illustrated a difference between the students with successful solution and students with incomplete solutions. The majority of students $(66.7 \%)$ who had successful solutions selected ideal materials for key acquisition. However, none of the students who had incomplete solutions selected ideal materials for key acquisition in their drawing. Fisher's exact probability test shows the difference is significant between the two successful and incomplete groups $(p=.001)$.

Table 9. Students' drawing of materials for key acquisition.

\begin{tabular}{cccc}
\hline & Successful Solution & Incomplete Solution & Whole Group \\
\hline $\begin{array}{c}\text { All Ideal Materials for } \\
\text { Key Acquisition }\end{array}$ & $16(66.7 \%)$ & $0(0 \%)$ & $16(51.6 \%)$ \\
\hline $\begin{array}{c}\text { Both Ideal \& Non- } \\
\text { Ideal Materials for Key } \\
\text { Acquisition }\end{array}$ & $1(4.2 \%)$ & $0(0 \%)$ & $1(3.2 \%)$ \\
\hline $\begin{array}{c}\text { Non Ideal or No } \\
\text { Materials for Key } \\
\text { Acquisition }\end{array}$ & $7(29.2 \%)$ & $7(100 \%)$ & $17(54.8 \%)$ \\
\hline
\end{tabular}

The selection of non-ideal materials indicates that while most students understood the conceptual requirement of acquiring the keys, some students did not understand or account for the constraints the box dimensions imposed on the materials they selected for key acquisition.

\section{Relationship between drawing of planned solution and constructed artifact}

The relationship between students' drawing of their planned solution and their constructed artifact was measured by how closely the drawing of their planned solution was related with their 
final artifact calculated using the Total Relationship Score (see Table 4). A Total Relationship Score was only calculated for students with successful solutions. Figure 10 shows the frequency of students by achieved Relationship Scores for successful solutions. The histogram shows that there was a wide range of relationships between drawing and final artifact. The relationship ranged from students who constructed an exact match of their drawing (Total Relationship Score $=6$ ) to those whose final artifact had little resemblance to their final artifact (Total Relationship Score=1).

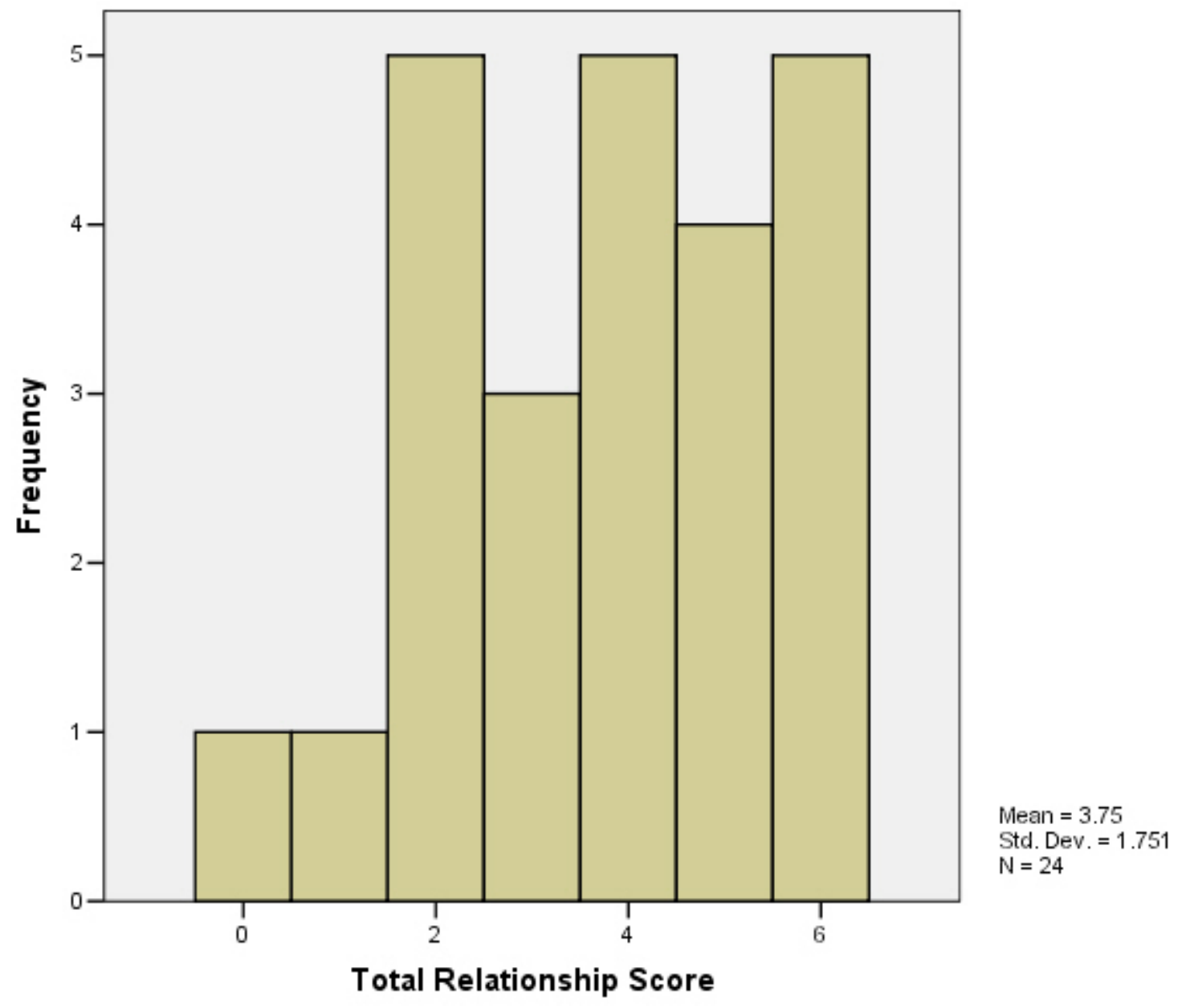

Figure 10. Histogram of Total Scores for students with successful solutions.

Grouping the Total Relationship Scores into three categories (see Table 10), we see that over half of the students with successful solutions had a strong relationship (High Total Relationship Score of 4-6) between their drawing and the artifact. This indicates that many students can engage in making most (if not all) of the choices about their solution prior to construction and also select most (if not all) of the materials they need when prior to construction. It also indicates that students carry ideas from the preliminary drawings to the construction of their artifact. However, $41.7 \%$ of the students (Low Total Relationship Scores of 1-3 or No Relationship) did not construct a solution that closely resembled what they planned. This split result raises the question 
of why students do or do not use their planning ideas in the construction of their artifact and is an area for future work.

Table 10. Total Relationship Scores in Groups.

\begin{tabular}{|l|l|}
\hline Total Score Categories & Number of Students \\
\hline High Total Relationship Scores (4-6) & $14(58.3 \%)$ \\
\hline Low Total Relationship Scores (1-3) & $9(37.5 \%)$ \\
\hline No Relationship (0) & $1(4.2 \%)$ \\
\hline Total & $24(100 \%)$ \\
\hline
\end{tabular}

Planning quality and drawing artifact relationship

To explore the reasons why students would or would not carry ideas from their drawing to their construction, the relationship between Total Drawing Score and Total Relationship Score was explored (see Figure 11). The hypothesis for this investigation was that students with high Total Drawing Scores, which would indicate they understood the problem requirements and selected ideal materials, would be more likely to use their ideas in the construction of their artifact. However, the results are inconclusive as graph illustrates that there is no clear relationship between the two scores. Similarly Kendall tau- $b=.311(\mathrm{p}=.063)$ shows a lack of a significant correlation between the two scores. This suggests that other factors (difficulty with construction, interest in other materials) may have influenced students to change their ideas from drawing to artifact. 


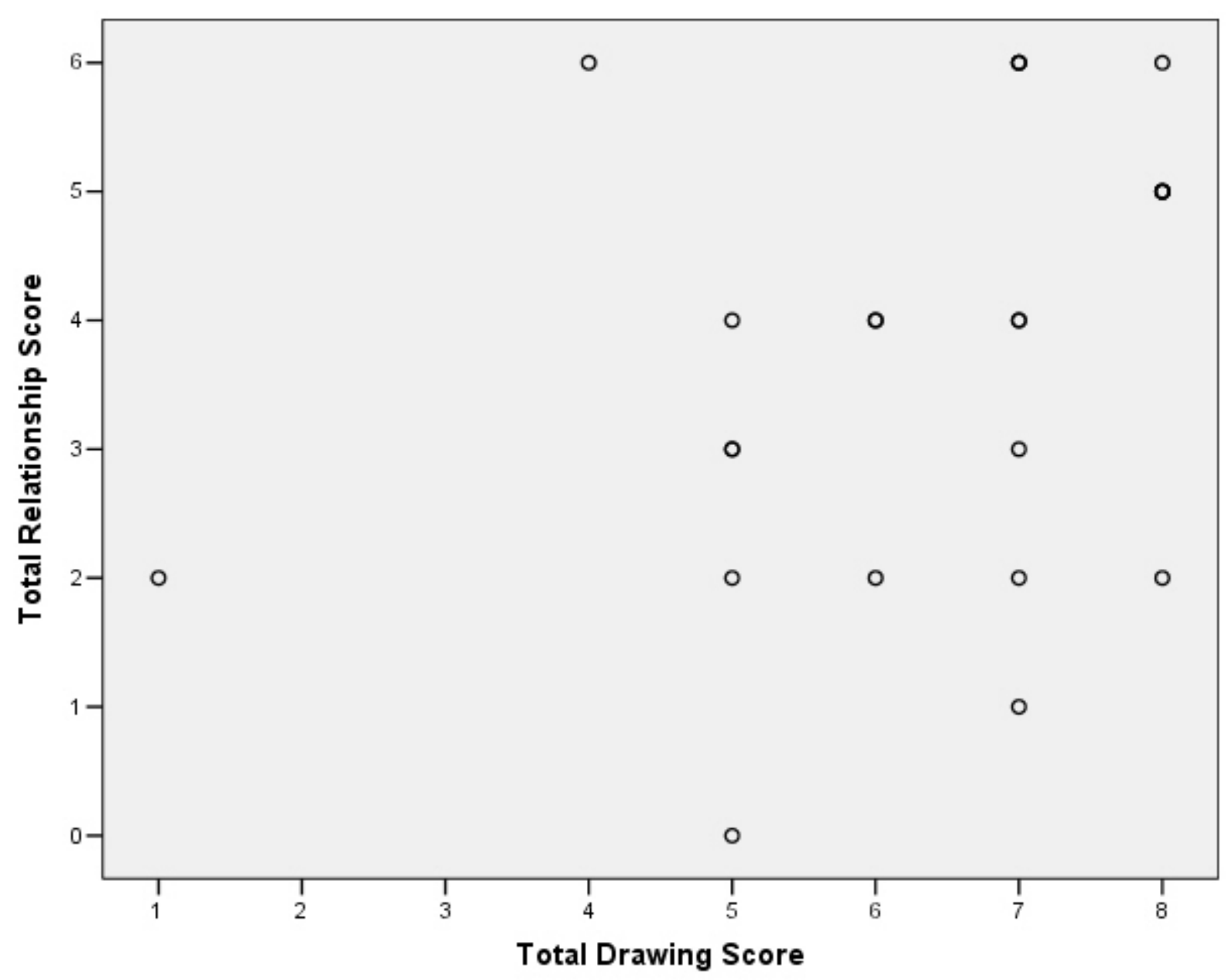

Figure 11. Total Drawing Score versus Total Relationship Score for Students with Successful Solutions.

To further explore the relationship between success and initial drawings in successful students, the relationship between Total Drawing Scores and Time to Completed Task was examined. It should be noted that students were not instructed to complete the task as quickly as possible to avoid anxiety from fear of failure. However, time to complete task was collected as a rough indicator of how easily students with successful solutions solved the task. Looking only at the students with successful solutions and their Total Drawing Score (see Figure 12) we see that there is a slight relationship between having accounted for the problem requirements with ideal materials (Total Drawing Score) and the time it took to complete the task. This relationship is not particularly strong $(\mathrm{R}$-squared $=0.11)$ nor does it yield a statistically significant correlation (.331 at the .114 level). This graph did not yield significant insight into what informs the time to completion of the task but suggests that quality of the initial drawing may predict how quickly the solution will be constructed and completed. 


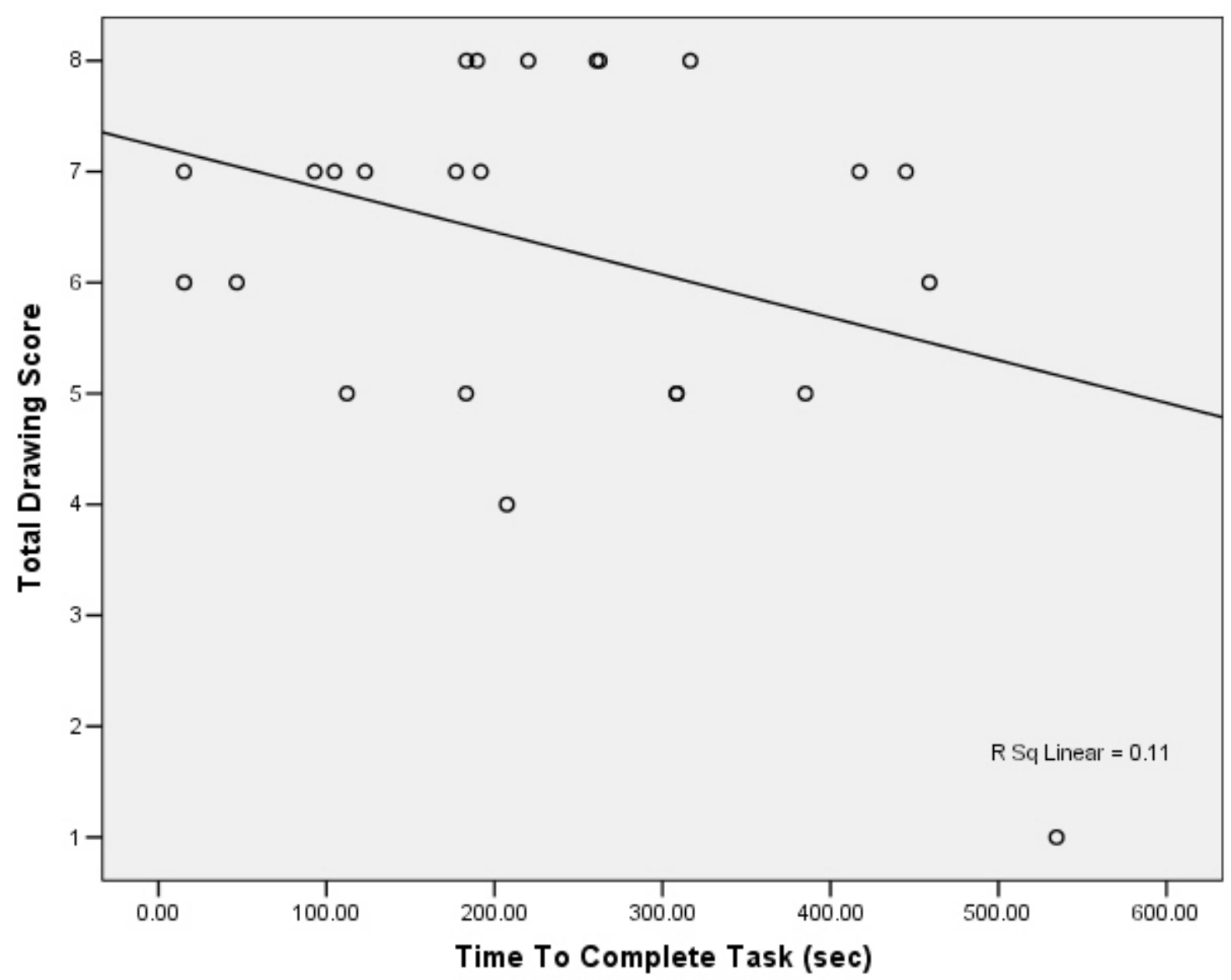

Figure 12. Graph of Time to Complete Task vs. Total Drawing Score.

However, looking at the Time to Complete Task versus Total Relationship Score (see Figure 13) we see a stronger relationship ( $\mathrm{R}$-squared $=.384)$ and a significant correlation $(-.620$ at the .01 level). 


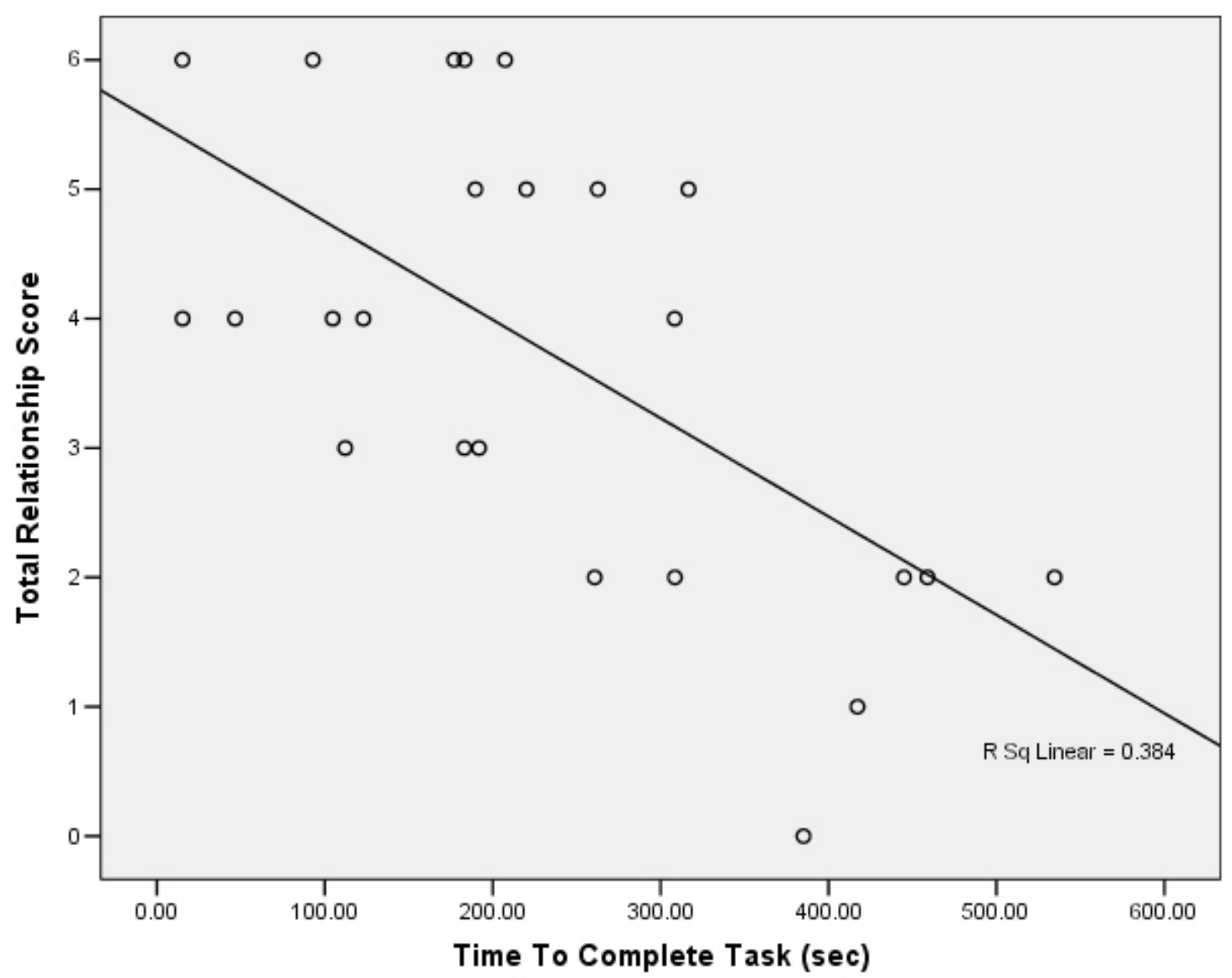

Figure 13. Time to Complete Task vs. Total Relationship Score.

Figure 12 and 13 combine to indicate that in this study the persistence of a student's ideas (Total Relationship Score) is a better predictor of time to complete task than just the quality of the idea (Total Drawing Score).

\section{Discussion, Implications and Conclusions}

The drawings that students produced prior to constructing their artifact indicated that a majority of first grade students could identify problem requirements (length and key acquisition, Table 6) and include relevant materials in their drawing without explicit instruction. It is meaningful to see that many young students can translate from ill-defined problem (retrieve the keys) to thinking about the specific materials they need to achieve this. The small minority for who were not able to do this might benefit from scaffolding that helped the student think through and decompose the problem ("Your arm can't reach the bottom of the box, what could you make/use to help you reach the bottom?"). The ability of many students to include sufficient materials for length (Table 7) and select the most useful (ideal) materials (Tables 8 \& 9) suggests that students are able to make meaningful choices at the drawing stage. This is significant because previous research ${ }^{17,18}$ was unclear as to whether students' drawing could be meaningful prior to their 
interaction with the materials. The use of craft materials that students are likely to have had previous experience with may have biased this result and future research in this area could try and account for students experience with the materials. The fact that a majority of students had a high Total Relationship Score (built an artifact similar to their drawing) as shown in Table 10 also supports the idea that first grade students are engaged in significant thought about their design ideas that may persist into the construction of their artifact.

While a majority of students created drawings that thoughtfully addressed requirements and selected ideal materials, it is unclear if those drawings served a planning purpose. The Total Drawing Score was not related to the Total Relationship Score (Figures 11). This indicates that students that created a drawing that indicated a strong understanding of the problem did not necessarily construct that solution. Total Drawing Score was also not related to Time to Complete Task (Figure 12). This suggests that the creation of a drawing that was likely to contain a successful solution did not impact the artifact students created or the time it took them to solve the challenge. These two results suggest that quality of the drawing is not necessarily a significant factor in completing the task. This may mean that for some first grade students the drawing is a representation of an idea they have mentally constructed while for others it may be an iteration in their thinking about a solution. The Total Relationship Score was significantly correlated with Time to Complete Task (Figure 13) which suggests that students persistence of ideas from drawing to artifact (good or bad) was a greater predictor of task efficiency that the quality of their drawn solution.

Combined these results suggest that while first grade students can be engaged in meaningful decision making at the preliminary drawing stage of design, they may not be using the drawing as planning the same way adults do and that this may vary greatly across students. The ability of students to address requirements and select materials implies that preliminary drawing can be included in first grade engineering design activities as a task that is within their reach. However, clearly more research is needed on how students create and use those drawings to inform their design as well as how to scaffold the creation and use of drawing as planning in early elementary classrooms. 


\section{References}

1. Jonassen, D.H., J. Strobel, and C.B. Lee, Everyday Problem Solving in Engineering: Lessons for Engineering Educators. Journal of Engineering Education, 2006. 95(2): p. 139-151.

2. $\quad$ French, M.J., Conceptual Design For Engineers. 1998, London: Springer.

3. Pahl, G. and W. Beitz, Engineering Design. 1984, New York: Springer-Verlag.

4. International Technology Education Association, Standards for Technological Literacy: Content for the Study of Technology. 2002, Reston, VA: International Technology Education Association.

5. Massachusetts Department of Education. Science and Technology/Engineering Curriculum Framework. 2001 [cited; Available from: http://www.doe.mass.edu/frameworks/scitech/1006.pdf.

6. $\quad$ Penner, D.E., R. Lehrer, and L. Schauble, From Physical Models to Biomechanics: A Design-Based Modeling Approach. The Journal Of The Learning Sciences, 1998. 7(3 \&4): p. 429-229.

7. $\quad$ Kolodner, J.L., et al., Problem-Based Learning Meets Case-Based Reasoning in the Middle-School Science Classroom: Putting Learning by Design Into Practice. The Journal of the Learning Sciences, 2003. 12(4): p. 495-547.

8. Fortus, D., et al., Design-Based Science and Student Learning. Journal of Research in Science Teaching, 2004. 41(10): p. 1081-110.

9. Welch, M., Analyzing the Tacit Strategies of Novice Designers. Research in Science \& Technology Education, 1999. 17(1).

10. Roden, C., How Children's Problem Solving Strategies Develop at Key Stage 1. The Journal of Design and Technology Education, 1999. 4(1): p. 21-27.

11. Johnsey, R. The place of the process skill making in design and technology: Lessons from research into the way primary children design and make. in IDATER95: International Conference on Design and Technology Educational Research and Curriculum Development. 1995. Loughborough, UK:Loughborough University of Technology.

12. Fleer, M., Interactive Technology: Can Children Construct Their Own Technological Design Briefs? Research in Science Education, 2000. 30(2): p. 241-253.

13. Gardner, W. and B. Rogoff, Children's Deliberateness of Planning According to Task Circumstances. Developmental Psychology, 1990. 26(3): p. 480-487.

14. Gauvain, M. and B. Rogoff, Collaborative Problem Solving and Children's Planning Skills. Developmental Psychology, 1989. 25(1): p. 139-151.

15. Anning, A., Dilemmas and Opportunities of a New Curriculum: Design and Technology with Young Children. International Journal of Technology and Design Education, 1994. 4: p. 155-177.

16. Roden, C. Young children's learning strategies in design and technology. in IDATER95: International Conference on Design and Technology Educational Research and Curriculum Development. 1995. Loughborough, UK:Loughborough University of Technology.

17. Rogers, G. and J. Wallace, The Wheels of the Bus: children designing in an early years classroom. Research in Science \& Technology Education, 2000. 18(1): p. 127-135.

18. $\quad$ Fleer, M., Working Technologically: Investigations into How young Children Design and Make During Technology Education. International Journal of Technology and Design Education, 2000. 10: p. 43-59. 


\section{APPENDIX A}

Coding for Length in Drawing.

\begin{tabular}{|c|c|c|c|}
\hline Addresses LENGTH & & 1 - Addressed & $\begin{array}{c}0-\text { Not } \\
\text { Addressed/Unclear }\end{array}$ \\
\hline $\begin{array}{l}\text { Enough } \\
\text { material(s) for } \\
\text { LENGTH } \\
\end{array}$ & $\begin{array}{l}2 \text { - Sufficient Materials ( } 2 \text { or more } \\
\text { materials that could reach the } 23 \text { " to the } \\
\text { bottom of the box) }\end{array}$ & $\begin{array}{l}\text { 1- Partial } \\
\text { Materials (too } \\
\text { short) }\end{array}$ & $\begin{array}{c}0 \text {-No } \\
\text { Materials/Unclear }\end{array}$ \\
\hline $\begin{array}{l}\text { Ideal Materials for } \\
\text { LENGTH }\end{array}$ & 2 - All Ideal Materials & $\begin{array}{l}1 \text { - Some Ideal } \\
\text { Materials }\end{array}$ & $\begin{array}{c}0-\text { No Ideal } \\
\text { Materials/Unclear }\end{array}$ \\
\hline $\begin{array}{l}\text { Material(s) used to } \\
\text { achieve LENGTH }\end{array}$ & $\begin{array}{l}\text { 0 None/Unknown } \\
1 \text { Magnet } \\
\text { 2 Pipe Cleaner } \\
\text { 3 Tape } \\
\text { 4 Paper Clip } \\
\text { 5 Spoon } \\
\text { 6 Clothespin } \\
7 \text { String } \\
\text { 8 Stick } \\
\text { 9 Pencil }\end{array}$ & & \\
\hline
\end{tabular}


APPENDIX B

Codes for analyzing key acquisition.

\begin{tabular}{|c|c|c|c|}
\hline Addresses Key Acquisition & & 1 - Addressed & $\begin{array}{c}0-\text { Not } \\
\text { Addressed/Unclear }\end{array}$ \\
\hline $\begin{array}{l}\text { Ideal Materials for Key } \\
\text { Acquisition }\end{array}$ & 2 - All Ideal Materials & $\begin{array}{l}1 \text { - Some Ideal } \\
\text { Materials }\end{array}$ & $\begin{array}{c}0 \text { - No Ideal } \\
\text { Materials/Unclear }\end{array}$ \\
\hline $\begin{array}{l}\text { Material used to achieve Key } \\
\text { Acquisition }\end{array}$ & $\begin{array}{l}0 \text { None/Unknown } \\
1 \text { Magnet } \\
\text { 2 Pipe Cleaner } \\
3 \text { Tape } \\
\text { 4 Paper Clip } \\
5 \text { Spoon } \\
6 \text { Clothespin } \\
7 \text { String } \\
\text { 8 Stick } \\
9 \text { Pencil }\end{array}$ & & \\
\hline
\end{tabular}

